\title{
PENGARUH PINJAMAN MODAL KERJA, PROFESIONALISME SUMBER DAYA MANUSIA TERHADAP LABA USAHA KECIL MENENGAH DI KECAMATAN BATANG KAPAS
}

\author{
MIKE YULIANI RESKI ${ }^{1}$, MUHAMMAD RIVANDI ${ }^{2}$ \\ Sekolah Tinggi Ilmu Ekonomi KBP \\ Email : ${ }^{1}$ mikhe10yuliani@gmail.com \\ ²muhammadrivandi@akbpstie.ac.id
}

\begin{abstract}
The purpose of this study was to determine the effect of working capital loans and the professionalism of human resources on the profits of small and medium enterprises. The research population of all small and medium nusiness profits in sub-district Batang kapas with sample selection full sampling as many 76 small and medium nusiness profits. Analysis method used multiple regression method. Regression results indicate that working capital loans are of significant value $0,00<0,05$ and the profesionalisme of human resources 0,263>0,05. Based on the results it can be concuded that working capital loans have a positive effect on small and medium nusiness profit while the profesionalisme of human resources does not affect the profit of small and medium nusiness profits.
\end{abstract}

Keywords: working capital loans, human resource professionalism, and small and medium business profits

\begin{abstract}
ABSTRAK
Tujuan penelitian ini adalah untuk mengetahui pengaruh pinjaman modal kerja dan profesionalisme sumber daya manusia terhadap laba usaha kecil menengah. Populasi penelitian seluruh UKM di kecamatan Batang Kapas dengan pemilihan sampel total sampling sebanyak 76 UKM. Metode analisis yang digunakan metode regresi berganda. Hasil regresi menunjukkan bahwa pinjaman modal kerja nilai signifikan $0,00<0,05$ dan profesionalisme SDM 0,263 >0,05. Berdasarkan hasil dapat disimpulkan bahwa pinjaman modal kerja berpengaruh positif terhadap laba UKM sedangkan profesionalisme SDM tidak berpengaruh terhadap laba UKM.
\end{abstract}

Kata Kunci : Pinjaman Modal Kerja, Profesionalisme Sumber Daya Manusia, Laba UKM 


\section{PENDAHULUAN}

UKM merupakan suatu bentuk usaha kecil masyarakat yang pendirinya berdasarkan inisiatif seseorang Sebagian besar masyarakat beranggapan bahwa UKM menguntungkan pihak pihak tertentu saja. UKM juga tidak berfokus dalam upaya pengembangan pasar sehingga tidak ada peningkatan penjualan.

Peningkatan UKM di Indonesia memiliki laba yang meningkat dan signifikan. Laba UKM adalah kenaikan modal (aktiva bersih) yang berasal dari semua transaksi atau kejadian lain yang mempengaruhi badan badan usaha pada suatu periode kecuali yang timbul dari pendapatan (revenue) atau investasi oleh pemilik. Laba sering diartikan sebagai total pendapatan dikurangi dengan total biaya yang dikeluarkan. Biaya-biaya yang dikeluarkan dapat berupa sejumlah pengeluaran kas yang digunakan untuk semua pembelian atau semua pembayaran yang terkait dengan operasional perusahaan Baridwan (1997). Biaya tersebut meliputi biaya upah dan gaji tenaga kerja, untuk memperoleh material, bunga kapital, sewa tanah dan bangunan, membeli peralatan, dan lain-lain. Laba yang dihitung berdasarkan pengurangan antara total pendapatan dengan explicit cost disebut dengan laba bisnis. Berbeda dengan laba ekonomi yang merupakan laba bisnis dikurangi lagi dengan implicit cost. Implicit cost ini meliputi nilai input yang dimiliki dan digunakan oleh perusahan.

Laba suatu perusahaan memberikan signal penting bagi perusahaan mengenal realokasi sumber daya dalam masyarakat, dimana hal tersebut mencerminkan perubahan kemampuan konsumen dan permintaan dalam suatu waktu. Laba sering diartikan sebagi total pendapatan dikurangi dengan total biaya yang dikeluarkan. Biaya biaya yang dikeluarkan dapat berupa sejumlah pengeluaran kas yang digunkan untuk semua pembelian dan semua pembayaran yang terkait dengan operasional perusahaan. Biaya tersebut meliputi biaya upah dan gaji tenaga kerja, untuk memperoleh material, bunga kapital, sewa tanah, bangunan dll Subramanyam, (2012).

Kredit modal kerja adalah kredit atau pinjaman yang diberikan untuk keperluan dalam meningkatkan produksi operasionalnya (Sari \& Rivandi, 2018). Dalam suatu bisnis besar seperti pada suatu perusahaan, memerlukan biaya yang tidak sedikit yang digunakan untuk berbagai macam keperluan mulai dari biaya produksi, biaya operasional mesin hingga biaya untuk membayar gaji karyawan Komaruddin (2005) dan (Oktaviani \& Rivandi, 2018)

Pengeluaran atau pemasukan perusahaan semuanya akan berhubungan erat dengan modal kerja tersebut tidak ada modal kerja maka akktivitas perusahaan tidak bisa berjalan dengan baik karena pengeluaran dan pemasukan perusahaan tidak tahu akan berhubungan dengan siapa (Okvineri \& Rivandi, 2018). Sebagai aktiva lancar, modal kerja dapat diklasifikasikan berdasarkan pada : a).Komponen kas, surat berharga, piutang dan persediaan. b). Waktu, yaitu permanen atau sementara.

Penelitian yang di lakukan oleh Yusriati, Arfan, \& Yahya (2001), Nurfarkhana (2015) dan Sasongko (2010) bahwa modal kerja berpengaruh terhadap laba UKM. Kenaikan pinjaman modal kerja akan meningkatkan porelahan laba di kota banda aceh, atau dengan kata lain UKM yang memiliki modal kerja yang lebih besar akan memperoleh laba yang lebih banyak. Modal kerja meupakan urat nadi bagi kelangsungan suatu perusahaan. Semakin besar 
modal kerja, maka semakin luas kesempatan untuk mengembangkan suatu usaha. Berdasarkan teori dan hasil penelitian terdahulu maka dapat diturunkan hipotesis yang akan dibuktikan secara empiris :

\section{$\mathrm{H}_{1}$ : Pinjaman modal kerja berpengaruh positif terhadap laba UKM}

Menurut Imawan (2009) Profesionalisme manunjukkan hasil kerja yang sesuai dengan standar teknisi atau etika sebua profesi. Aktivitas kerja itu lazim berhubungan dengan penghasilan dalam bentuk uang. Tingkat profesionalisme sumber daya manusia memiliki harus dipenuhi antara lain kemampuan memberikan pelayanan, disiplin, bertindak sesuai tanggung jawab,kemampuan menarik konsumen.

SDM sebagai salah satu sumber keunggulan kompetitif dapat dikelola untuk membangun kompetensi organisassional Pengembangan dan penggunaan kompetensi transformasional melalui sistem SDM dapat memupuk dan mendorong akumulasi pengetahuan organisasional melalui inovasi, entrepreneurship, budaya organisasi, dan pembelajaran organisasi yang diperlukan untuk mengubah input menjadi output dilakukan dengan cara menciptakan komitmen karyawan terhadap suatu perusahaan, memupuk idiosyncratic (pencarian peluang dan interprestasi spesifikasi perusahaan dan simbol pengetahuan), serta membangun membangun kinerja organisasi yang positif (Nurjannah, 2015).

Penelitian yang dilakukan oleh Yusriati et al. (2001) bahwa profesionalisme berpengaruh terhadap laba UKM. Karena meningkatnya profesionalisme karyawan akan meningkatkan perolehan laba UKM di Kota banda aceh. Begitu juga dengan menurutnya profesionalisme pegawai (pengalaman kerja) 1 tahun maka akan menurunkan nilai perolehan laba UKM. Setiap kenaikan profesionalisme (pengalaman kerja) pagawai 1 tahun maka akan meningkatkan nilai laba UKM.

Profesionalisme sumber daya manusia dapat meningkatkan laba dari UKM Keahlian dalam mengelola usaha maka dapat mempengaruhi usaha menjadi lebih maju berdasarkan pengalaman yang telah dimiliki membuat pengusaha dapat memberikan pembaharuan terhadap usaha.

Berdasarkan teori hasil penelitian terdahulu maka dapat diturunkan hipotesis yang jika dibuktikan secara empiris bahwa :

\section{$\mathrm{H}_{2}$ : Profesionalisme SDM berpengaruh positif terhadap laba UKM}

\section{METODE PENELITIAN Data dan Sampel}

Jenis penelitan yaitu menggunakan data kuantitatif. Dimana data kuantitatif yang berupa angka disebut juga dengan data kuantitatif, dimana jenis data kuantitatif ini dapat dikelompokkan menjadi dua macam, data kontinue dan data diskrit. Data kontinue merupakan pengukuran data tersebut yang diperoleh dari hasil penelitiannya sedangkan data diskrit merupakan hasil yang menghitung data yang diperoleh membilang (tidak pengukur) (Sugiyono, 2015). Peneliti menggunakan data kontinue seperti pinjaman modal kerja, dan laba usaha kecil menengah 
Populasi adalah wilayah generalisasi yang terdari atas obyek atau subyek yang mempunyai kualitas dan karakteristik tertentu yang ditetapkan oleh peneliti untuk dipelajari dan kemudian ditarik kesimpulannya.

Teknik sampel yang digunakan peneliti yaitu Total sampling Menurut (Sugiyono, 2015) Total sampling adalah teknik pengambilan sampel dimana jumlah sampel sama dengan populasi. Sampel di dalam penelitian ini seluruh UKM di Kecamatan Batang kapas dengan jumlah sampel 76 UKM.

\section{Definisi Operasional Variabel}

\section{Tabel 1}

Gambar Definisi Operasional

\begin{tabular}{|l|l|l|l|}
\hline No & \multicolumn{1}{|c|}{ Variabel } & \multicolumn{1}{|c|}{ Defenisi } & Pengukuran \\
\hline 1 & $\begin{array}{l}\text { Pinjaman } \\
\text { Modal Kerja } \\
\left(\mathrm{X}_{1}\right)\end{array}$ & $\begin{array}{l}\text { Modal Kerja menurut Munawir (2005) } \\
\text { adalah kelebihan nilai aktiva yang } \\
\text { dimiliki perusahaan terhadap seluruh } \\
\text { hutang hutangnya. }\end{array}$ & $\begin{array}{l}\text { Total Pinjaman } \\
\text { Pihak Ketiga }\end{array}$ \\
\hline 2 & $\begin{array}{l}\text { Profesionalis } \\
\text { me }\left(\mathrm{X}_{2}\right)\end{array}$ & $\begin{array}{l}\text { Menurut (Yusriati et al., 2001) } \\
\text { mengemukakan bahwa propesionalisme } \\
\text { merupakan suatu paham tentang cara } \\
\text { dan kinerja dalam suatu masyarakat. }\end{array}$ & $\begin{array}{l}\text { Pama Berdiri } \\
\text { Perusahaan }\end{array}$ \\
\hline 3 & Laba (Y) & $\begin{array}{l}\text { Laba merupakan kelebihan total } \\
\text { pendapatan dibandingkan total } \\
\text { bebannya. Laba disebut juga } \\
\text { pendapatan bersih atau net earnings } \\
\text { (Sartono, 2010) }\end{array}$ & $\begin{array}{l}\text { Jumlah Laba } \\
\text { Usaha }\end{array}$ \\
\hline
\end{tabular}

\section{Teknik Analisis Data}

Tahapan dalam pengelolaan data dalam penelitian menggunakan bantuan program SPSS 23. Model penelitian yang digunakan analisis Model Regresi Berganda dimana mengetahui pengaruh Pinjaman Modal Kerja, Profesionalisme SDM Terhadap Laba UKM di Kecamatan Batang Kapas . Model Analisis dapat dirumuskan kedalam bentuk persamaan berikut ini :

$$
Y=\beta_{0}+\beta_{1} P M K_{X 1}+\beta_{2} P S D M_{x 2}+e
$$

Berdasarkan model Regresi Berganda menjelaskan bahwa Y merupakan Laba UKM, PMK merupakan Pinujaman Modal Kerja, PSDM merupakan Profesionalisme Sumber daya manusia , $\beta_{0}$ merupakan Konstanta, $\beta_{1}-\beta_{4}$ merupakan Koefisien regresi dan terakhir e merupakan error. 


\section{Pengujian Hipotesis}

Pengujian hipotesis yang dilakukan menggunakan menggunakan pengujian $\mathrm{t}$ statistik dan pengujian koefisien determinasi ( $R$-Square) yaitu dengan menggunakan program Eviews 9. Koefisien determinasi (R-Square) menjelaskan tentang seberapa kemampuan model dalam merangkan variabel independen (variabel bebas) berpengaruh terhadap variabel independen (variabel terikat). Koefisien variabel dependen dalam penelitian adalah enterprise risk management disclosure, dewan komisaris independen, dan komite audit sedangkan variabel variabel dependen adalah nilai perusahaan. Secara umum kriteria yang digunakan meliputi 1) Nilai $\mathrm{R}^{2}$ yang kecil atau mendekati nol, berarti kemampuan variabel bebas dalam menjelaskan variasi variabel tidak bebas dan sangat terbatas. 2) Nilai $\mathrm{R}^{2}$ mendekati satu, berarti kemampuan variabel-variabel bebas dalam menjelaskan hamper semua informasi yang digunakan untuk memprediksi variasi variabel tidak bebas (Gujarati, 2008)

Pengujian $\mathrm{t}$ statistik merupakan suatu uji statistik yang digunakan untuk melihat sejauh mana pengaruh variabel independen terhadap variabel secara parsial atau individu dimana kriteria dididalam pengambilan kepetusannya adalah Kriteria Pengujian adalah 1) Jika probabilitas $\leq$ alpha 0,05 maka keputusannya adalah Ho ditolak dan Ha diterima maka dapat disimpulkan bahwa variabel independen berpengaruh signifikan terhadap variabel dependen secara individual. 2) Jika probabilits > alpha 0,05 maka keputusannya adalah Ho diterima dan $\mathrm{Ha}$ ditolak maka dapat disimpulkan bahwa variabel independen tidak berpengaruh signifikan terhadap variabel dependen secara individual (Gujarati, 2008).

\section{HASIL DAN PEMBAHASAN Statistik Deskriptif}

Tabel 2

Hasil statistik deskriptif

\begin{tabular}{|l|r|r|c|r|r|}
\hline & N & Minimum & Maximum & Mean & \multicolumn{1}{c|}{ Std. Deviation } \\
\hline Pinjaman Modal Kerja & 76 & 300000000.00 & 1576000000.00 & 804410526.3158 & 306753733.39926 \\
Profesionalisme & 76 & 3.00 & 22.00 & 12.5263 & 4.76787 \\
Laba & 76 & 216320000.00 & 1159680000.00 & 674750921.0526 & 231478516.45356 \\
Valid N (listwise) & 76 & & & & \\
\hline
\end{tabular}

Sumber : olah data statistik SPSS 232018

Dilihat pada gambaran statistik deskriptif pada tabel 4.1 bahwa dapat dijelaskan bahwa data nilai pinjaman modal kerja yang paling kecil yaitu sebesar Rp. 300.000.000 sedangkan pinjaman modal kerja yang paling besar yaitu senilai Rp. 1.576.000.000. Secara keseluruhan pada umumnya data yang digunakan pada penelitian ini memiliki rata rata pinjaman modal kerja yaitu senilai $\mathrm{Rp}$. 804.410.526,31 lebih besar dari standar deviasi yang didapatkan senilai Rp. 
306.753.733,39 maka data bernilai positif.

Data nilai profesionalisme yang paling kecil yaitu sebesar 3 tahun sedangkan profesionalisme yang paling besar yaitu sebesar 22 tahun. Secara keseluruhan pada umumnya data yang digunakan pada penelitian ini memiliki rata rata profesionalisme yaitu senilai 12,25 tahun lebih besar dari standar deviasi yang didapatkan senilai 4,76 maka data bernilai positif.

Data nilai laba UKM yang paling kecil yaitu sebesar Rp. 216.320.000 sedangkan laba UKM yang paling besar yaitu senilai Rp. 1.159.680.000. Secara keseluruhan pada umumnya data yang digunakan pada penelitian ini memiliki rata rata laba UKM yaitu senilai Rp. 674.750.921,05 lebih besar dari standar deviasi yang didapatkan senilai Rp. 231.478.516,45 maka data bernilai positif.

\section{Koefisien Determinan (R-Squere)}

\section{Tabel 3}

\section{Pengujian Koefisien Determinan (R-Squere)}

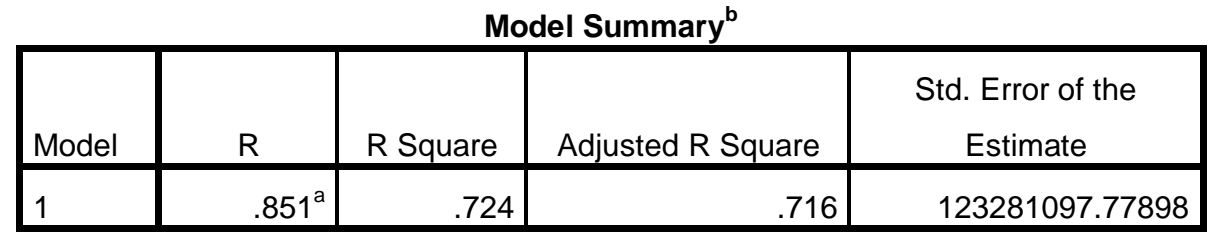

a. Predictors: (Constant), Profesionalisme, Pinjaman Modal Kerja

b. Dependent Variable: Laba

Sumber : olah data statistik SPSS 232018

Dari gambaran uji determinan pada tabel 4 bahwa dapat menjelaskan bahwa nilai $R$ Square adalah sebesar 0,716 . Di sini dijelaskan bahwa besarnya pengaruh variabel pinjaman modal kerja dan profesionalisme terhadap laba UKM adalah sebesar $71,6 \%$ dan sisanya sebesar $28,4 \%$ dipengaruhi oleh variabel lain selain dari modal yang diteliti.

Tabel 4

\section{Hasil Uji Regresi Linear Berganda}

Coefficients $^{a}$

\begin{tabular}{|c|c|c|c|c|c|c|}
\hline \multirow[b]{2}{*}{ Model } & \multicolumn{2}{|c|}{ Unstandardized Coefficients } & \multirow{2}{*}{$\begin{array}{c}\text { Standardized } \\
\text { Coefficients } \\
\text { Beta }\end{array}$} & \multirow[b]{2}{*}{$\mathrm{t}$} & \multirow[b]{2}{*}{ Sig. } & \multirow[b]{2}{*}{ Kesimpulan } \\
\hline & $\mathrm{B}$ & Std. Error & & & & \\
\hline (Constant) & 139474620.892 & 43873728.608 & & 3.179 & .002 & \\
\hline Pinjaman Modal Kerja & .599 & .059 & .793 & 10.135 & .000 & SIGNIFIKAN \\
\hline Profesionalisme & 4284855.529 & 3800540.551 & .088 & 1.127 & .263 & TIDAK SIGNIFIKAN \\
\hline
\end{tabular}

a. Dependent Variable: Laba

Sumber : olah data statistik SPSS 232018 
Dari hasil diatas dapat diperoleh persamaan regresi Berganda

$$
Y=139.474 .620,892+0,599 X_{1}+4.284 .855,529 X_{2}+e
$$

Berdasarkan analisis regresi berganda dapat diinterpretasikan bahwa nilai konstanta yang dihasilkan adalah sebesar Rp. 139.474.620,892 nilai yang diperoleh tersebut mengisyaratkan bahwa jika diasumsikan tidak terjadi perubahan (peningkatan atau penurunan) variabel Pinjaman Modal Kerja dan Profesionalisme SDM maka nilai dari variabel Laba UKM adalah sebesar Rp. 139.474.620,892

Didalam model persamaan regresi berganda juga terlihat bahwa variabel Pinjaman Modal Kerja memiliki nilai koefisien regresi bertanda positif sebesar Rp. 0,599. Nilai koefisien yang diperoleh menunjukan bahwa ketika diasumsikan terjadi peningkatan nilai pinjaman modal kerja yang dimiliki usaha kecil menengah di Kecamatan Bayang sebesar 1 Rp akan meningkatkan Laba UKM sebesar Rp. 0,599 dengan asumsi faktor lain selain Pinjaman Modal Kerja dianggap tetap atau konstan.

Didalam model persamaan regresi berganda juga terlihat bahwa variabel Profesionalisme SDM memiliki nilai koefisien regresi bertanda positif sebesar Rp. 4284.855,529. Nilai koefisien yang diperoleh menunjukan bahwa ketika diasumsikan terjadi peningkatan nilai Profesionalisme SDM yang dimiliki usaha kecil menengah di Kecamatan Bayang sebesar 1 tahun akan meningkatkan Laba UKM sebesar Rp. 4284.855,529 dengan asumsi faktor lain selain Profesionalisme SDM dianggap tetap atau konstan.

\section{Pengujian Hipotesis Pinjaman Modal Kerja terhadap Laba UKM}

Berdasarkan hasil pengujian hipotesis pertama dengan menggunakan variabel Pinjaman Modal Kerja diperoleh nilai sig sebesar 0,000. Di dalam tahapan pengujian digunakan tingkat kesalahan sebesar 0,05 . Hasil yang diperoleh menunjukan bahwa nilai signifikansi sebesar $0,000 \leq$ alpha 0,05 maka keputusannya adalah Ho ditolak dan Ha diterima sehingga dapat disimpulkan bahwa Pinjaman Modal Kerja berpengaruh positif dan signifikan terhadap Laba UKM

\section{Pengujian Hipotesis Profesionalisme SDM terhadap Laba UKM}

Berdasarkan hasil pengujian hipotesis kedua dengan menggunakan variabel Profesionalisme SDM diperoleh nilai sig dari pengujian sebesar 0,263. Proses pengolahan data dilakukan degan menggunakan tingkat kesalahan sebesar 0,05 . Hasil yang diperoleh tersebut menunjukan bahwa nilai probability sebesar $0,263 \geq$ alpha 0,05 maka keputusannya adalah Ho diterima dan Ha ditolak sehingga dapat disimpulkan bahwa Profesionalisme SDM tidak berpengaruh terhadap Laba UKM 


\section{Pembahasan}

\section{Pengaruh Pinjaman Modal Kerja Terhadap Laba UKM}

Berdasarkan hasil pengujian hiopotesis pertama menunjukkan bahwa pinjaman modal kerja berpengaruh positif dan signifikan terhadap laba UKM. Hasil penelitian yang telah dilakukan dapat diinterpretasikan bahwa pinjaman modal kerja berpengaruh positif dan signifikan terhadap laba UKM di Kecamatan Batang Kapas. Hasil tersebut sama dari teori modal kerja merupakan urat nadi bagi kelangsungan suatu perusahaan. Semakin besar modal kerja, maka semakin luas kesempatan untuk mengembangkan usaha Tumanggor, Dahen, \& Saputra, (2016).

Kredit modal kerja adalah kredit atau pinjaman yang diberikan untuk keperluan dalam meningkatkan produksi operasionalnya. Dalam suatu bisnis besar seperti pada suatu perusahaan, memerlukan biaya yang tidak sedikit yang digunakan untuk berbagai macam keperluan mulaidari biaya produksi, biaya operasional mesin hingga biaya untuk membayar gaji karyawan Komaruddin (2005). Artinya kredit modal kerja dipergunakan untuk meningkatkan laba perusahaan tersebut dimana penggunaan kredit modal kerja diperuntukkan untuk meningkatkan aktivitas operasional perusahaan. Sehingga nantinya akan meningkatkan pendapatan yang mana pendapatan tersebut akan menghasilkan laba yang cukup signifikan. Hasil penelitian ini juga menyimpulkan bahwa semakin tinggi kredit modal kerja yang diterima oleh perusahaan maka akan semakin tinggi laba yang akan diperoleh oleh perusahaan tersebut. Ada banyak faktor yang mempengaruhi pinjaman modal kerja terhadap laba yaitu adanya kebutuhan akan tambahan modal sehingga dengan adanya tambahan modal tersebut maka operasional perusahaan dapat ditingkatkan sehingga akan menghasilkan laba yang lebih tinggi nantinya.

Perkembangan rata-rata pinjaman modal kerja dari UKM yang ada di Kecamatan Batang Kapas adalah sebesar Rp. 80s4.410.526,3 dengan rata-rata laba adalah sebesar Rp. 674.750.921,1. Disini bahwa sebagian besar dari pinjaman modal kerja yang diperoleh oleh UKM dapat menghasilkan laba perusahaan sehingga akan memiliki pengaruh yang cukup signifikan.

\section{Pengaruh Profesionalisme SDM Terhadap Laba UKM}

Berdasarkan hasil pengujian hiopotesis pertama menunjukkan bahwa profesionalisme tidak berpengaruh terhadap laba UKM. Menurut Imawan (1999) Profesionalisme menunjukkan hasil kerja yang sesuai dengan standar teknis atau etika sebuah profesi. Aktivitas kerja itu lazim berhubungan dengan pengasilan dalam bentuk uang. Konsep profesionalisme sumber daya manusia yang harus dimiliki atau dipenuhi yaitu: kemampuan menarik konsumen, kemampuan memberikan pelayanan, disiplin, bertindak sesuai tanggung jawab. Selain itu juga diperlukan untuk menumbuh kembangkan jiwa entrepreneur dalam diri individu seperti kreativitas SDM.SDM yamg baik mengedepankan kejujuran dan kemampuan bekerja sama dengan baik (Ismanto, 2009).

Hasil penelitian yang telah dilakukan dapat diinterpretasikan bahwa Profesionalisme sumber daya manusia tidak berpengaruh terhadap laba UKM pada Kecamatan Batang Kapas. Artinya disini bahwa profesionalisme suatu perusahaan dalam menciptakan laba tidak tergantung dari berapa lama perusahaan itu berdiri karena sifat dari laba tersebut adalah sesuai dengan reaksi pasar yang 
terjadi serta perubahan harga yang terjadi yang nantinya akan mempengaruhi laba perusahaan itu sendiri. Artinya disini seberapa besarpun profesionalisme perusahaan dari sumber daya manusianya tidak akan mempengaruhi perolehan laba yang diperoleh nantinya, karena ada banyak faktor selain dari profesionalisme yang dapat mempengaruhi laba tersebut, karena kompetensi seseorang tidak dapat diukur melalui berapa lama seseorang bekerja dalam satu perusahaan jika tidak diimbangi dengan faktor luar yang mungkin saja bisa mempengaruhi laba tersebut. Hal ini mungkin saja terjadi apabila seseorang jika semakin profesionalisme yang tinggi dalam bekerja maka akan semakin tinggi risiko kecurangan yang mungkin saja dapat dilakukan oleh orang tersebut, sehingga tidak akan mempengaruhi laba perusahaan.

\section{Simpulan}

Berdasarkan hasil analisis data dan pembahasan yang telah dikemukakan pada bab sebelumnya dapat diambil beberapa kesimpulan sebagai beriku: 1) Pinjaman Modal Kerja berpengaruh positif dan signifikan terhadap Laba UKM di Kecamatan Batang Kapas 2) Profesionalisme SDM tidak berpengaruh terhadap Laba UKM di Kecamatan Batang Kapas

\section{UCAPAN TERIMA KASIH}

Peneliti mengucapkan terima kasih kepada Kementrian Koperasi dan Usaha Kecil menengah yang telah berkenan membantu dengan memberikan data laporan keuangan penelitian ini.

\section{DAFTAR PUSTAKA}

Baridwan. (1997). Intermediate Accouting. Yogyakarta: Salemba Empat.

Gujarati. (2008). Basic of Econometrica. McGraw-Hill, Irwin.

Imawan, R. (1999). Profesionalisme Bidang Politik dan Swadaya Masyarakat. Proceding Universitas Sumtera Utara, 77.

Ismanto, K. (2009). Manajemen Syariah. Yogyakarta: Pusstaka Pelajar.

Komaruddin. (2005). Dasar Dasar Manajemen Modal Kerja. Jakarta: Rineka Cipta.

Munawir, S. (2005). Analisis Laporan Keuangan. Yogyakarta: Liberty.

Nurfarkhana, A. (2015). Pengaruh Modal Kerja Terhadap Laba Usaha Pada Koperasi Serba Usaha Sejati Mulia Jakarta. Sosio-E-KONS, 7(3), 181-186.

Nurjannah, S. (2015). Pengaruh Pembiayaan Modal Kerja, Profesionalisme Sumber Daya Manusia dan Lama Usaha Terhadap Laba. STAIN PEKALONGAN.

Oktaviani, \& Rivandi, M. (2018). Tingkat Suku Bunga dan Kredit Macet Pengaruhnya Terhadap Permintaan Kredit UMKM di Pasaman Barat (Studi Kasus KSU LKMA KaMPUNG Solok Saiyo Nagari Muara Kiawai. INA- 
Rxiv. https://doi.org/10.17605/OSF.IO/N4YZS

Okvineri, M., \& Rivandi, M. (2018). Pengaruh Efisiensi Biaya Dan Modal Sendiri Terhadap Tingkat Kesehatan Koperasi Pada Koperasi Pegawai Republik Indonesia ( KPRI ) Guru / Karyawan Depdikbudcam Lubuk Begalung. INARxiv. https://doi.org/10.31227/osf.io/s67pt

Sari, M. P., \& Rivandi, M. (2018). Pengaruh Modal Sendiri Dan Modal Pinjaman Pada Koperasi Di Kota Padang. INA-Rxiv, 1-12. https://doi.org/10.31227/osf.io/867y9

Sartono, R. A. (2010). Manajemen Keuangan Teori dan Aplikasi (4th ed.). Yogyakarta: BPFE.

Sasongko, S. N. (2010). Pengaruh Modal Kerja dan Volume Penjualan Terhadap Laba Bersih. Universitas Komputer Indonesia.

Subramanyam, K. . (2012). Analisis Laporan Keuangan (Edisi 10). Jakarta: Salemba Empat.

Sugiyono. (2015). Statistika untuk Penelitian. Bandung: Alfabeta.

Sugiyono. (2016). Metode Penelitian (23rd ed.). Bandung: AlfaBeta.

Tumanggor, M., Dahen, L. D., \& Saputra, S. E. (2016). Pengaruh Biaya Operasional, Volume Penjualan Modal Kerja, dan Perputaran Total Aktiva Terhadap Laba Bersih Perusahaan Sub Sektor Logam dan Sejenisnya Yang Terdaftar Di Bursa Efek Indonesia. Jurnal Ekonomi STKIP PGRISumatera Barat.

Yusriati, C., Arfan, M., \& Yahya, M. R. (2001). Pengaruh Pinjaman Modal Kerja, Profesionalisme Sumber Daya Manusia Terhadap Laba Usaha Kecil Menengah Kota Banda Aceh. Jurnal Akuntansi Pascasarjana Universitas Syiah Kuala, 1(I), 28-40. 